\title{
La constitución de la subjetividad en la educación contable: del proceso implícito a la visibilización de sus impactos*
}

doi:10.11144/Javeriana.cc15-37.csec

\section{Carlos Mario Ospina-Zapata}

Profesor del departamento de Ciencias Contables, Universidad de Antioquia. Magíster en Ciencias de la Administración, en curso, Universidad EAFIT. Contador público, Universidad de Antioquia. Integrante del Grupo de Investigaciones y Consultorías en Ciencias Contables, GICCO, Universidad de Antioquia.

Correo electrónico: cmospinaz@gmail.com

\section{Mauricio Gómez-Villegas}

Profesor de la Escuela de Administración y Contaduría, Universidad Nacional de Colombia. Doctor en Contabilidad, Universitat de València. DU Sciences de Gestion, Université de Rouen. Magíster en Administración y contador público, Universidad Nacional de Colombia, UNAL. Miembro del grupo de investigación Contabilidad, Organizaciones y Medioambiente, Universidad Nacional de Colombia, UNAL y del Centro Colombiano de Investigaciones Contables, C-CINCO.

Correo electrónico: mgomezv@unal.edu.co

\begin{abstract}
William Rojas-Rojas
Profesor del Departamento de Contabilidad y Finanzas, Universidad del Valle. Doctorante de Ciencias de Gestión, Conservatoire National des Arts et Métiers, CNAM, Francia. DEA en Desarrollo de Recursos Humanos del CNAM. MSc en organizaciones, contador público y licenciado en filosofía y letras, Universidad del Valle. Director del grupo de investigación Nuevo Pensamiento Administrativo, Universidad del Valle.
\end{abstract}

Correo electrónico: wilrojas5@hotmail.com 
Resumen La subjetividad puede ser entendida como la condición que le permite a cada sujeto autorreferirse respecto de sí y de su contexto. Podemos estar frente a un sujeto que cuida de sí y de los otros (sapientia), o frente a un sujeto que no desarrolla ejercicios y prácticas conscientes para esculpir una imagen de sí (stultitia). La educación tiene profundos impactos en la constitución de la subjetividad. Particularmente, la educación contable no ha prestado atención a la formación de la subjetividad en las dimensiones complejas de la persona-profesional. Pero esta falta de atención no significa que no se participe en la constitución de un tipo de subjetividad. En este trabajo nos preguntamos: ¿qué tipo de subjetividad se construye desde la educación contable actual? Planteamos que, por medio de contenidos conceptuales (la visión financiera del mundo social), valores implícitos y explícitos (individualismo, egoísmo, emprenderismo, exitismo) y mecanismos de disciplinamiento formal (códigos éticos y estándares profesionales, entre otros), se participa en la constitución de una subjetividad caracterizada en la actualidad por el predominio de la formación que hace al sujeto competente en ciertos ejercicios profesionales, profundamente débil en comprensiones contextuales y de alta incapacidad para problematizarse frente a la complejidad del mundo de la vida. Señalamos que la educación contable actual debe conmover sus bases estructurantes para facilitar procesos de resubjetivización en el estudiante de contaduría pública.

Palabras clave autor: subjetividad; educación contable; formación contable

Palabras claves descriptor: subjetividad; contadores- responsabilidad profesional; contaduría como profesión

Códigos JEL: A 22, M 41

\section{Constitution of Subjectivity in Accounting Education: from the Implicit Process to Making its Impact Visible}

\begin{abstract}
Subjectivity can be understood as the condition that allows every subject to self-refer regarding himself and his context. We could be in front of a subject that takes care of himself and others (sapientia) or in front of a subject that does not perform exercises and conscious practices to sculpt an image of himself (stultitia). Education has a deep impact on the constitution of subjectivity. In particular, accounting education has not paid attention the building of subjectivity in the complex dimensions of the personprofessional. But this lack of attention does not mean that there is no participation in the building of a type of subjectivity. In this work we ask: What kind of subjectivity is built from current accounting education? We pose that through conceptual contents (the financial vision of the social world), implicit and explicit values (individualism, selfishness, endeavor, successfulness) and formal discipline mechanisms (ethic codes and professional standards, among other), we take part in the construction of a subjectivity, currently characterized by the prevailing of an education that makes the subject competent in certain professional exercises, deeply weak in contextual understanding, and highly incapable to question himself in front of the complexity of the world of life. We point out that current accounting education must shift its structuring foundations to make processes of reconstruction of subjectivity easier to the public accounting student.
\end{abstract}

Key words author: subjectivity; accounting education; accounting training

Key words plus: subjectivity; accountants - malpractice; accounting as profession

\section{Constituição da subjetividade na educação contábil: do processo implícito à visibilização dos seus impactos}


Resumo A subjetividade pode ser entendida como a condição que lhe permite a cada sujeito se autorreferir respeito de si e de seu contexto. Podemos estar de frente para um sujeito que cuida de si e dos outros (sapientia), ou frente de um sujeito que não desenvolve exercícios e práticas conscientes para esculpir uma imagem de si (stultitia). A educação tem profundos impactos na constituição da subjetividade. Particularmente, a educação contábil ainda não prestou atenção à formação da subjetividade nas dimensões complexas da pessoa-profissional. Embora, esta falta de atenção não significa que não se participa na constituição de um tipo de subjetividade. Neste trabalho nos perguntamos: que tipo de subjetividade se constrói desde a educação contábil atual? Levantamos que, por meio de conteúdos conceituais (a visão financeira do mundo social), valores implícitos e explícitos (individualismo, egoísmo, empreendedorismo, exitismo) e mecanismos de disciplinamento formal (códigos éticos e padrões profissionais, entre outros), participa-se na constituição de uma subjetividade caracterizada na atualidade pelo predomínio da formação que faz ao sujeito competente em certos exercícios profissionais, profundamente fraco em compreensões contextuais e de alta incapacidade para se problematizar frente à complexidade do mundo da vida. Assinalamos que a educação contábil atual deve comover suas bases estruturantes para facilitar processos de resubjetivação no discente de Contabilidade Pública.

Palavras-chave autor: subjetividade; educação contábil; formação contábil

Palavras-chave descritor: subjetividade; contadores - etica profissional; contadores

Un rasgo general - un principio fundamental-es que el sujeto en tanto tal, tal como se da a sí mismo, no es capaz de la verdad. Y no es capaz de verdad, salvo si opera, si efectúa en sí mismo una cantidad de operaciones, una cantidad de transformaciones $y$ modificaciones que lo harán capaz de verdad... uno no puede tener acceso a ella (verdad) si no cambia su modo de ser.

Michel Foucault (2006, p. 189)

\section{Introducción}

La subjetividad, según el DRAE ${ }^{1}$, es un sustantivo que demuestra la cualidad de lo subjetivo. ¿Y qué indica la palabra subjetivo?, que es un adjetivo que puede usarse de dos formas: a) perteneciente o relativo al sujeto, considerándolo en oposición al mundo externo; b) relativo a nuestro modo de pensar o sentir, y no al objeto en sí mismo. No obstante, para esta disertación, es importante dejar claro que cuando nos referimos a la palabra subjetividad, estamos entendiendo no un mero adjetivo, sino un concepto que da cuenta de un sujeto que piensa y siente desde un marco referencial que le permite leer y problematizar su contexto y su tiempo. En este sentido, entendemos la subjetividad como el conjunto de actitudes y prácticas que le permiten a cada sujeto esculpir una forma de verse y de constituirse permanentemente, para desde allí relacionarse con los otros y con su contexto.

Con la frase proemial - que antecede este trabajo-, queremos remarcar que el concepto de subjetividad ha sido muy significativo para proyectar las orientaciones morales y políticas de los individuos en Occidente ${ }^{2}$. Dicho de otro modo, el tema de la subjetividad tiene qué ver con los corpus filosóficos que pretenden

1 Diccionario de la Real Academia de la Lengua Española. 2 Foucault (2001/2008). La hermenéutica del sujeto. Este texto hace una brillante referencia a la forma en que el pensamiento occidental ha construido los referentes filosóficos para comprender las múltiples formas de autoconocimiento humano. 
explicar las actitudes, las preocupaciones y las acciones (Foucault, 2001/2008) que les permiten a los individuos autorreferenciarse y crear una imagen de sí en relación con un deber ser que necesariamente trasciende sus vivencias y/o experiencias singulares. La subjetividad da cuenta de los acoplamientos y distanciamientos de un sujeto con respecto a su existencia y a su entorno. En toda persona se expresa, de una u otra manera, una forma de vivir, resultado de actitudes y ejercicios para forjar su lugar en el mundo.

En términos filosóficos, hacerse sujeto de $s i^{i}$ es el resultado de una serie de reproches, de una reflexión lúcida y crítica que facilita que el sujeto se instale en el mundo de una forma que reconoce los límites y las posibilidades de la condición humana. Consideramos fundamental aceptar que la universidad, como institución de servicio público, debe comprometerse con la formulación de proyectos educativos como un medio ("instrumento", "herramienta") para que la comunidad que habita en ella, pueda repotenciar su proceso de subjetivación.

Creemos que en sus pregrados, la universidad debe facilitar que los estudiantes reflexionen sobre el lugar desde el cual ellos piensan los tabúes y las normas que los sujetan a su cultura y a su sociedad. En lo sucesivo, partimos de considerar que la universidad, como institución formadora, debe jugar un papel central en la constitución de la subjetividad de sus estudiantes. Por ello, planteamos que el rol de la universidad trasciende la búsqueda de capacitación para la adquisición de competen-

3 Esta expresión es tomada literalmente de Michel Foucault (2001/2008). cias operativas o académicas. Consideramos, en sintonía con lo planteado por Ronald Barnett, que la universidad debe jugar un rol central en la potenciación de los sujetos para participar y comprender el mundo de la vida (Barnett, 2001). De no ser así, la universidad pierde su horizonte formativo misional: formar un ser humano capaz de desubjetivarse y resubjetivarse en el reacomodamiento de las dimensiones éticas y políticas que facilitan anteponerse a la irrebasable e indeterminada maldad humana.

Lo que nos interesa remarcar es un punto de vista que Michel Foucault (2001/2008, p. 134) retoma de unos planteamientos que Séneca le presenta a Lucilio y a Sereno, y que resultan fundamentales para señalar que la subjetividad como inquietud de sí no es un proceso que nazca y emerja por la mera existencia humana:

(...) esa agitación del pensamiento, esa irresolución es en suma lo que llamamos stultitia (...) es algo que no se fija ni se complace en nada. Nadie tiene una buena salud suficiente (satis valet) para salir por sí mismo de ese estado (salir: emerger). Es preciso que alguien le tienda la mano y lo saque: oportet aliquis educat (...).

(...) [Sereno] voy a darte el diagnóstico que te corresponde, $y$ te diré exactamente en qué estás. Pero para hacerte comprender con claridad en qué estás, te describiré antes que nada el peor estado en que uno puede encontrarse $y$, a decir verdad, el estado en el cual nos encontramos cuando no hemos comenzado aún el camino de la filosofía, ni el trabajo de la práctica de sí. Cuando todavía 
no hemos cuidado de nosotros mismos, estamos en ese estado de stultitia

Para describir con mayor detalle el pensamiento de Séneca sobre el estado de stultitia, presentamos las siguientes líneas de Foucault:

Así pues, la stultitia, es, si lo prefieren, el polo opuesto a la práctica de sí. (...) El stultus ${ }^{4}$ es quien no se preocupa por sí mismo. (...) quien ante todo está expuesto a todos los vientos, abierto al mundo externo, es decir, quien deja entrar a su mente todas las representaciones que ese mundo externo puede ofrecerle. Representaciones que acepta sin examinarlas, sin saber analizar qué representan. El stultus está abierto al mundo externo en la medida en que deja que esas representaciones, en cierto modo, se mezclen dentro de su propio espíritu - con sus pasiones, sus deseos, sus ambiciones, sus hábitos de pensamiento, sus ilusiones, etcétera-, de modo que es, entonces la persona que está expuesta a todos los vientos de las representaciones externas y luego, una vez que estas han entrado en su mente, es incapaz de hacer la división, la discriminatio entre el contenido de esas representaciones y los elementos que nosotros llamaríamos, si ustedes quieren, subjetivos, que se mezclan en ella (...) El stultus es quien está disperso en el tiempo: no solo abierto a la pluralidad del mundo exterior, sino disperso en el tiempo. El stultus es quien no se acuerda de nada, quien deja que su vida pase, quien no

4 Foucault hace referencia al texto de Séneca, De la tranquillité de l'âme. trata de llevarla a una unidad rememorando lo que merece recordarse, y [quien no dirige] su atención, su voluntad, hacia una meta precisa y bien establecida. El stultus deja que la vida pase y cambia de opinión sin respiro. Por consiguiente, su vida, su existencia, transcurre sin memoria ni voluntad. Por eso hay en él un perpetuo cambio de modo de vida (...) Séneca decía: en el fondo nada es más nocivo que cambiar de modo de vida con los años, y tener uno cuando somos adolescentes, otro cuando somos adultos, un tercero cuando somos viejos (...) El stultus es quien no piensa en su vejez, quien no piensa en la temporalidad de su vida, tal como esta debe polarizarse en la consumación de sí en la vejez. Es quien cambia de vida sin descanso (...) El individuo stultus no es capaz de querer como es debido (...). La voluntad del stultus es una voluntad que no es libre (...). Es una voluntad que no siempre quiere. ¿Qué significa querer libremente? Significa que uno quiere, sin que lo que quiere esté determinado por tal o cual acontecimiento, tal o cual representación, tal o cual inclinación. Querer libremente es querer sin ninguna determinación, mientras que el stultus está determinado, a la vez, por lo que procede del exterior y lo que viene del interior (...). Vale decir que el stultus quiere varias cosas a la vez, y esas cosas son divergentes sin ser contradictorias. Por lo tanto, no quiere una y absolutamente una sola. El stultus quiere algo y al mismo tiempo lo lamenta. Así, quiere la gloria y, al mismo tiempo, lamenta no llevar una vida tranquila, voluptuosa, etcétera (...). El stultus es quien quiere, pero 
quiere también con inercia, quiere con pereza, su voluntad se interrumpe sin descanso, cambia de objetivo. No siempre quiere. Querer libremente, querer absolutamente, querer siempre: eso es lo que caracteriza el estado opuesto a la stultitia. Y la stultitia, por su parte, es esa voluntad, voluntad en cierto modo limitada, relativa, fragmentaria y cambiante (...). El stultus es en esencia quien no quiere, quien no se quiere a sí mismo, quien no quiere el yo, cuya voluntad no está encauzada hacia ese único objeto que se puede querer libremente, absolutamente y siempre y que es el sí mismo. En la stultitia hay una desconexión, una no conexión, una no pertenencia entre la voluntad y el yo, que es característica de ella y, a la vez, su efecto más manifiesto y su raíz más profunda. Salir de la stultitia será, justamente, actuar de modo tal que se pueda querer el yo, que uno pueda quererse a sí mismo, tender hacia sí mismo como único objeto que es posible querer libremente, absolutamente, siempre (...). Entre el individuo stultus y el individuo sapiens es necesario el otro (...). La cuestión que se plantea, entonces es la siguiente: ¿cuál es la acción del otro que es necesaria para la constitución del sujeto por sí mismo? ¿Cómo llega esta acción del otro a inscribirse como elemento indispensable en la inquietud de sí? (Foucault, 2001/2008, pp. 135-139).

Por lo anterior, podemos hablar de una subjetividad compleja (rica en posibilidades y resultado de una práctica de sí, en los términos de Foucault) o de una subjetividad empobrecida y chata (estado de stultitia). Desde que haya persona, habrá subjetividad y por consiguiente, se puede establecer un juicio valorativo de las actitudes y de las formas de ver de todos los sujetos. Todo individuo vive y actúa en unas coordenadas histórico-sociales que dan cuenta de su constitución y los impactos de instalarse en el mundo de tal o cual manera. Hay un mundo que ata al sujeto y hay unas formas de vida que le facilitan retirarse de las relaciones de poder instrumentales.

Preguntar por un tipo de subjetividad asociado a una profesión, como en este caso la de contador(a) público(a), es intentar indagar cómo desde los programas de contaduría pública es posible contribuir a que los estudiantes que se encuentren en el estado del stultus ${ }^{5}$ puedan abandonarlo. En esencia, un programa debe educar para desarrollar un tipo de voluntad que les facilite a los estudiantes esculpir su sí mismo, su yo. Por múltiples razones - que no podemos precisar aquí-, creemos que muchos de los miembros de la comunidad estudiantil participantes de los programas de contaduría pública requieren conectar su voluntad con su yo y ahí los programas deberían fijar gran parte de su labor educativa. La cuestión no es fácil, pero un currículo de pregrado que circunscriba sus acciones a la educación meramente funcional o académica traiciona su propia razón de ser.

\footnotetext{
5 Nuestra pretensión no es la de hacer un señalamiento negativo. No nos interesa decir: los estudiantes de contaduría pública son stultus. Nos convoca el poder comprender los vericuetos de una subjetividad que se niega a proyectarse crítica y constructivamente frente al mundo de la vida. Nuestra idea enfatiza que es necesario que intentemos comprendernos en nuestro presente para mejorar las intervenciones que como profesores podemos hacer en los proyectos formativos.
} 


\section{A propósito del sujeto en el currículo de contaduría pública}

A los programas llegan jóvenes que no necesariamente están conscientes del propio estado de su subjetividad. Ana María Fernández en su trabajo de psicoanalista ha identificado en las formas de vida y los relatos de sí de algunos jóvenes, unas modalidades muy similares al sujeto stultus, lo que en ella aparece como "jóvenes de vidas grises", seres que dimensionan su existencia como un: "hacer lo que se espera, vivir en lo que es, vivir con lo dado (...) como si hubiera una ausencia de anhelo o valoración de construir las propias experiencias, o de transformar o innovar en las propias condiciones de existencia” (2013, p. 20). Por tanto, y ante estas formaciones de la personalidad, siempre es necesario preguntar por la subjetividad del estudiante que ingresa (perfil de ingreso) y la subjetividad del profesional (perfil de egreso) que se desea ofrecer a la sociedad; se trata de constituir un tipo de nuevo sujeto profesional; un alguien que sea capaz de repotenciar su estructura de relacionamiento social y profesional, a partir de la identificación con su yo ${ }^{6}$ personal.

6 Para Foucault, el yo organizó o reorganizó efectivamente el campo de los valores tradicionales del mundo helenístico clásico. El yo “(...) se presenta como un valor universal, pero que de hecho solo es accesible a algunos. Ese yo no puede alcanzarse concretamente como valor salvo que exista cierta cantidad de conductas reguladas, exigentes y sacrificiales (...)". Este acceso al yo está asociado a una serie de técnicas, de prácticas relativamente bien constituidas, relativamente bien meditadas, y de todas maneras asociadas a un dominio teórico, a un conjunto de conceptos y nociones que lo integran realmente a un modo de saber (Foucault, 2008, p. 179).
Atendiendo el planteo de Foucault sobre lo que indica la noción de sujeto en filosofía (1988, p. 7), todo currículo y toda práctica pedagógica deben reconocer que "hay dos significados de la palabra sujeto: sometido al otro a través del control y la dependencia, y sujeto: atado a su propia identidad por conciencia o el conocimiento de sí mismo". La educación del stultus, por tanto, se preocupa por sujetar al control, generando dependencia. En este sentido, la filosofía del currículo debe dejar claro cómo, desde los saberes que en ella confluyen, se piensa potenciar la subjetividad de sus actores, en sintonía con la segunda concepción foucaultiana del sujeto. Los discursos y dispositivos pedagógicos pueden, primero, desujetar y resujetar al individuo con su entorno y sus perspectivas de sí mismo y, segundo, proveer teorías y conceptos que promuevan la problematización y la reconducción de su propia conducta ${ }^{7}$.

Se ha planteado que entre las prácticas, discursos y dispositivos más significativos para la constitución del sujeto, la institución escolar juega un papel determinante (Blackman, Cromby, Hook, Papadopoulos \& Walkerdine, 2008). En general, todo el aparato educativo participa en la constitución de la subjetividad, en uno u otro sentido, de sus participantes. En el campo de la educación contable, pocos

\footnotetext{
7 Desde este punto de vista, el poder no es fundamentalmente la capacidad de coerción sobre otros (lo que es la dominación), sino la capacidad de influir en otros. La forma en que se construye la subjetividad, en últimas, define las relaciones de poder. "Lo que define una relación de poder es que es un modo de acción que no actúa de manera directa e inmediata sobre los otros, sino que actúa sobre sus acciones" (Foucault, 1988).
} 
trabajos han problematizado explícitamente la constitución de la subjetividad (McPhail, 1999). Pero hay toda una línea de investigación que aborda el rol de la contabilidad en la construcción de personas gobernables (Miller \& O'Leary, 1987/2009; Mennicken \& Miller, 2012). Por consiguiente, podemos plantear que la dinámica histórica de la enseñanza universitaria y el telos contemporáneo de la profesión y de la disciplina contables deben apuntar a ofrecer conceptos, valores, pautas y reglas que contribuyan a que los estudiantes puedan potenciar su yo, para desde ahí, participar tanto en su reconstitución subjetiva, como en los fines nobles que se derivan del saber contable. Por esta razón, conviene preguntarnos: ¿qué tipo de subjetividad se construye desde los proyectos educativos contables existentes en Colombia?

Para abordar esta pregunta, primero sintetizamos las coordenadas histórico-sociales de los sistemas de pensamiento que caracterizan a los sujetos premoderno, moderno y posmoderno, pues, como señala Fernando CruzKronfly (2012), en las culturas híbridas, como la nuestra, coexisten, sin ninguna dificultad, varios sistemas de pensamiento en la mente de un mismo individuo. Luego, presentamos una visión panorámica global del rol de la educación en la constitución de las subjetividades en la actualidad. Finalmente, trazamos, a mano alzada, algunos elementos para interpretar el papel de la educación contable en la reconstitución de la subjetividad de quienes estudian contaduría pública.

\section{El sujeto y sus coordenadas histórico-sociales}

Sin agotar otras opciones de caracterización, quizás más abarcativas, podemos señalar panorámica y sistemáticamente que en Occidente ha habido varios tipos de sistemas de pensamiento que permiten hablar de una subjetividad premoderna o tradicional, una moderna y otra posmoderna o hipermoderna. También podríamos hablar de algunas particularidades del tipo de pensamiento latinoamericano (García-Canclini, 1995). Pero dado que cada vez más Latinoamérica queda presa de la expansión cultural eurocéntrica y angloamericana, resulta ilustrativo comprender algunas características de los sistemas de pensamiento que se pueden encontrar, ya sea de manera aislada o entreverada, en las mentes que pueblan la geografía colombiana.

El sujeto premoderno se caracteriza por su

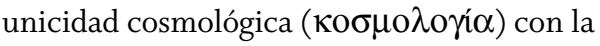
naturaleza, a partir de ciertas reverencias casi siempre vinculadas a una deidad. Lo propio de este sujeto es asumir como suyas las tareas que le vienen encomendadas como mandato divino. Las reglas sociales son reproducidas por la tradición, enmarcada en actos de reverencia y sumisión que garantizan un orden duradero en la relación amo-esclavo, padre-hijo, etc. El despliegue central de una subjetividad en este sistema se ubica en la obediencia absoluta a las leyes divinas y en la reverencia a las formas de gobierno que prohíjan y mantienen este orden social. El mito y el rito son los relatos y espacios que cohesionan y hacen que perdure la tradición. No es necesario explicar con detalle en 
qué sentido la época denominada Edad Media, y aun en el período del Renacimiento, estaban dominadas por una perspectiva monoteísta (y teocrática) en el marco del ritual judeo-cristiano (católico y posteriormente, las religiones derivadas de él), en el que las personas debían regir su comportamiento en función de las santas escrituras y el mandato divino traducido por los sacerdotes.

Por su parte, el sistema de pensamiento moderno da lugar a la emergencia de un sujeto escindido de la naturaleza en el sentido de unidad cosmológica. El imaginario moderno instaura un descentramiento de la fuerza divina como el punto cero de la explicación de los designios de la humanidad; este sujeto no aparece de la nada sino que resulta del conjunto de contradicciones que ya en las postrimerías de la Edad Media empiezan a observarse. Nuevas formas de economía (comercio), reconocimiento de otros (lo musulmán), la domesticación de cierta naturaleza inhóspita en principio (tecnología), la introducción de los números arábigos y el pensamiento aristotélico en la versión de Averroes (filosofía natural), las discusiones en el seno mismo de la Iglesia entre nominalistas y realistas, la reinterpretación del relato bíblico, entre otras situaciones (Romero, 1987), son el conjunto de raíces que soportan y posicionan ese nuevo sujeto que empieza a despuntar: el sujeto burgués que más adelante será concebido como el sujeto de la modernidad. El sistema de pensamiento moderno promueve un sujeto que reclama para sí la posibilidad del conocimiento autónomo que le permita disponer de sus sentidos. La naturaleza empieza a ser dibujada como una exterioridad que puede ser domesticada al servicio infinito del progreso humano. En la modernidad, el hombre se ubica en el centro de la cosmovisión (antropocentrismo) y desplaza a lo divino; Descartes brinda un nuevo método para conocer e instaura una nueva lógica de la verdad que, con el tiempo, se consolida amparada en la demostración experimental y en las matemáticas. El mundo empieza a ser codificado de forma espectacular por la ciencia y la tecnología, a partir de la creación y manipulación de objetos naturales y artificiales. La época que ha logrado disminuir el poder clerical — no sin sacrificios-, empieza a producir su propia forma de asociación y gobierno en los denominados “Estados Nación”. El capitalismo como base de las relaciones económicas florece con una de sus más interesantes producciones: las sociedades de encierro escenificadas en la fábrica y en la sofisticación del sistema escolar, hospitalario y carcelario, entre otras (Foucault, 1986). El individuo plenipotente dueño del mundo e inspirador de las más complejas e interesantes revoluciones científicas se autorreferencia delirantemente.

El sistema de pensamiento moderno en su forma más pura promueve la emergencia de sujetos capaces de generar los mecanismos sociales para el gobierno de sí mismos. La nueva subjetividad que impone cuestiona las verdades dogmáticas porque se cree en disposición de prolongar la curiosidad al infinito (mayoría de edad). Desde el sistema de pensamiento moderno, se proclamó que la igualdad, la fraternidad y la libertad eran los pilares de la dignidad humana; se fundó el mito del progreso anclado en que la ciencia, el poder del Estado-nación y la economía industrial harían a los hombres más 
libres en un ambiente de inclusión y justeza. En este marco, persiste una subjetividad en la que se configura esa otredad que garantiza una cierta trinidad: el sujeto, el otro con el que se "habla" y un tercero de lo que tiene sentido hablar (Dufour, 2007a, 2007b). Este sujeto está convencido de esos "metarrelatos" como los lugares para cultivar las más estilizadas y defendibles aspiraciones de la humanidad.

Pero al parecer, ni la ciencia ni el Estado nación ni la emancipación del proletariado ni los otros grandes relatos de la modernidad han facilitado asir una sociedad como la prometida. Dos guerras mundiales y la inhumanidad de la barbarie mostraban al mundo cómo las subjetividades modernas, tan sigilosamente construidas, resultaban imperfectas (Giddens, 1996). Mostraban cómo una educación sintonizada con las mejores producciones culturales no garantizaba un piso ético para la acción humanizante y dignificante (Bauman, 2007). Y quizá esto haya sido así, porque en los últimos siglos, de todas las producciones de la modernidad, inevitablemente, la atención se fue desplazando a la economía de mercado - aquella cimentada en un tipo de racionalidad científico-técnica de cuño positivista e instrumental-y a unas relaciones sociales gobernadas por el egoísmo y la avaricia sin límites, estas últimas proclamadas como virtudes públicas y principios promotores del éxito generalizado. Grandes acontecimientos del siglo XX indican que las máximas filosóficas kantianas se quedaron en propósitos y la subjetividad crítica, como ideal, empezó a desvanecerse por la hegemonía de un mercado naturalizado y profundamente excluyente (Giddens, 1996).
En este contexto, se empieza a configurar un nuevo tipo de sujeto stultus (que aún se sigue configurando y que coincide con lo que se ha dado en llamar el sujeto posmoderno) descreído y escéptico; un sujeto que empieza a ver el presente, lo que trae cada día, como la aspiración de más largo plazo para su vida. Un sujeto que, desmontado de los grandes relatos de la modernidad, señala que la ciencia es solo una de tantas formas de acercarse a la verdad, que de manera contradictoria construye una idea de la diversidad y de lo microsociológico. En algunas ocasiones, reclama la individualidad y la diversidad como derechos propios, pero en otras ve a los demás como extraños y surgen nuevas identidades de cuño neotribal, basadas en la diferenciación y la exclusión.

El nuevo sujeto stultus no cree en el Estado, en la democracia ni en la representación política y por lo tanto se declara "apolítico" (Hardt \& Negri, 2012); el nuevo sujeto stultus cargado de temores e ilusiones acude a las formas hedónicas de primera mano, los narcóticos y los antidepresivos; a su pensamiento no le importa la verdad (cada quien tiene su verdad, diría el sujeto posmoderno), porque la verdad está en cada subforma social (de allí la cantidad de grupos: raperos, metaleros, harlistas, emo, verdes, etc.) que reclaman para sí su legitimidad. El nuevo sujeto stultus no necesita pensar por sí mismo, el tiempo lo lleva; se virtualiza y prefiere el holograma del otro a su forma real. Advertimos los referentes del neostultus en Dany Robert Dufour (2007b, p. 34), cuando señala: “En la postmodernidad democrática, no se define ya el sujeto por su dependencia y su sumisión al gran Sujeto [metarrelato], sino por su autono- 
mía jurídica, por su total libertad económica, y se da una definición autorreferencial del sujeto parlante" (la ausencia de esa tercería de la que hemos hablado antes).

Al nuevo sujeto stultus se le imposibilita imaginar cómo los mass media le imponen unos valores y unas expectativas éticas y estéticas para vivir. Sin saberlo, el nuevo stultus se ahoga indoloramente en sus obediencias vanas al presente. Siguiendo los planteamientos de Ana María Fernández, los jóvenes de vidas grises (para nuestro caso, neostultus) viven el presente bajo la lógica del consumo inmediatista que les impide intentar romper las rutinas: "la vida transcurre entre el desinterés y los terrores (...) no aparecen motivos, fuerzas, razones, para frenar los excesos y quedan abandonados/as a los violentamientos de sí y de otros, sin poder operar las simbolizaciones que dieran ligadura a lo salido del cauce" (2013, p. 30, p. 36).

Recapitulando, podemos decir que el sistema de pensamiento moderno, sintetizado entre otros por Immanuel Kant, René Descartes, Thomas Hobbes y Nicolás Maquiavelo, brindaba una importante promesa de recomprensión de las explicaciones que se ofrecían desde los imaginarios premodernos y los sistemas de la organización feudal. Pero los desarrollos funcionales y los instrumentos burocráticos para jalonar el progreso, dieron vida al "todo vale" y desde allí emergieron grandes procesos de alivianamiento de las racionalidades ${ }^{8}$ (que se preocupaban por cultivar la inquietud de sí) que reconfiguraron no solo el capitalismo de

8 Nos referimos a la pluralidad de formas de comprensión y significación que tejen los humanos en contextos históricos y culturales determinados (Leff, 2004). mercado en su nueva fase de explotación financiarizada, sino unos ciertos tipos de poder que perforaron los valores que fundaban el telar del sistema de pensamiento moderno. Dicho de otro modo, el capitalismo en su forma mercantil, políticamente más desregulada, aprovechó el malestar del sujeto moderno (sus críticas) para reestrategizar a su favor unos nuevos valores que resujetaban a los hombres a huir de la inquietud de sí. Dany Robert Dufour (2007b, p. 36) precisa muy bien el repliegue del capitalismo, en la siguiente sentencia:

La economía de mercado juega sobre el registro libidinal al presentarle a cada sujeto un objeto manufacturado que, se supone, satisfará su deseo (...). El sujeto postmoderno se concibe, en adelante, como una condición subjetiva definida por un estado límite entre la neurosis y la psicosis, más y más preso de la melancolía latente, la imposibilidad de hablar en primera persona, la ilusión de omnipotencia y en fuga hacia delante de los falsos self, en personalidades prestadas, incluso múltiples, ofrecidas en profusión por el mercado.

Justa y subrepticiamente ese mercado pretende instaurarse como el gran sujeto de la contemporaneidad (metarrelato) y para ello requirió de un biopoder que ajustara los fenómenos de población a los procesos económicos (Fernández, 2013, p. 67). Bajo el biopoder, en la clave psicoanalítica que desarrollan Ana María Fernández y Dany Robert Dufour, puede decirse que estamos presenciando la emergencia de nuevas subjetivaciones: personas dóciles, 
incapaces de repensarse ante los nuevos simbolismos y convencionalismos de su época, temerosas y sedientas de objetos, frugales y livianos, también compulsivas y obesas, esquizoides, narcisas, pero también depresivas, incapaces de hacerse preguntas, pragmáticas, apáticas, desinteresadas y caracterizadas por el avasallamiento de sus necesidades múltiples e infinitas. Como advierte el mismo Dufour (2007b), el mercado no logra proveerle al sujeto las respuestas más importantes de su frágil yo, aquellas relacionadas con su propia fundación.

Lo anterior, aunque bien podría plantearse para una evaluación del proceso educativo en un entorno internacional, es quizá un mapa muy específico pero sugerente para pensar las diferentes formas de subjetividad que se pueden ofrecer desde las coordenadas histórico-sociales de un país que, como Colombia, gravita entre la violencia salvaje, la corrupción y el marco inquebrantable del ultraliberalismo económico.

\section{El rol de la educación en la constitución de la subjetividad}

Como se ha dicho antes, partimos de reconocer que la finalidad de la educación universitaria es repotenciar la problematización lúcida de la sujeción - consciente o inconsciente-de los estudiantes. En especial, el reto de educar está en no castrar la potencia de la formación de cada sujeto, o lo que Cruz-Kronfly ha descrito "como la necesidad psíquica de 'verdad' que anida en el espíritu de todos los seres humanos, desde los tiempos ancestrales hasta nuestros días" (1998). Por consiguiente, hay algo que perturba al sujeto stultus y que reta el quehacer de las instituciones que deben educar. Estamos ante el reto de aportar a la constitución de un profesional capaz de reconsiderar la forma deseante que lo sujeta a negarse a des-componer su proyecto de vida, es decir, sus modalidades de existencia.

El papel crucial de las universidades en términos de su función formativa es instaurar currículos y prácticas pedagógicas que faciliten que los estudiantes salgan de la positivización que, según Édgar Gracia-López: “ha otorgado primacía a los objetos, ignorando o desconociendo la inserción plena de los sujetos en los procesos del descubrimiento y contextualización de la realidad (...) en este proceso el sujeto ha resultado petrificado sin más atributo que la práctica ciega y muda ante los problemas de la sociedad" (2010, p. 258). Los currículos deben permitir señalizar la construcción cultural de la época; deben proponerle rutas al estudiante de comprensión de su presente y de la forma en que asume una "postura” que él piensa libre y autoinducida, pero que resulta condicionada por las instituciones y el momento histórico que vive. En la educación, ese estudiante debe reconocerse como híbrido ya no solo racialmente sino en términos de lo que le asiste como cultura y como posibilidad cognitiva y perceptiva.

Por ejemplo, en el caso de la sociedad colombiana, el reto es aún mayor porque nos asiste, como diría Cruz-Kronfly (1998), un mestizaje, una suerte de bricolaje, de entrecruzamiento de sistemas de pensamiento y 
de prácticas cotidianas que nos dificultan repensarnos, desde lo que Foucault rescató de la cultura helenística y romana: el cuidado de su propio yo, la inquietud de sí: épiméleia heauto $\hat{u}^{9}$. Creemos que los agentes partícipes $^{10}$ en los programas de contaduría pública de Colombia no pueden quedarse perplejos, cuando en ellos (los programas) se inscriben, por ejemplo, estudiantes que intentan acercarse a la disciplina contable -inmanente a un mundo racional, lógico y comprometido con la creación, interpretación y divulgación de la información económica, financiera, social y medioambiental de las organizaciones - con un desconocimiento casi total de las lógicas de la razón y la experimentación científica, de la misión de la universidad como espacio privilegiado para el cultivo y desarrollo de las "verdades" científicas, desprovistos de entender el lugar y los desasosiegos del pensamiento secular que pone en tela de juicio la fe, apropiados de prejuicios ideológicos, con grandes vacíos en la formación matemática y en las ciencias humanas y sociales. ¿No estamos obligados a pensar nuestros proyectos formativos? ¿No están los programas ante un nuevo íncipit ${ }^{11}$, que nos obliga a construir unas nuevas gramáticas para la creación y la formación de nues-

9 Foucault rescató de la cultura helenística, de la cultura grecorromana, desde el siglo III a.C. y hasta el siglo II o III d.C., el término griego Épiméleia heautoû como una frase muy poderosa que quiere decir: "Trabajar en o estar muy interesado por algo (...) describe un tipo de trabajo, de actividad; implica atención conocimiento y técnica" (Foucault, 2009, p. 71).

10 Profesores, gestores curriculares, directivos y estudiantes, entre otros.

11 Íncipit, según George Steiner, es una orgullosa palabra latina que indica que el inicio sobrevive en nuestra polvorienta palabra "incipiente" (Steiner, 2012, p. 11). tros amigos del pensamiento contable? ¿Qué puede hacer la universidad para ayudarles a los estudiantes a descifrar y a complejizar su subjetividad, su capital simbólico, su ética y su estética? ¿Acaso el reto de la educación universitaria contable no es turbar para potenciar la dimensión social de la disciplina y enaltecer nuestros preceptos éticos?

El panorama de la educación universitaria de la contaduría pública en Colombia, en general, puede concebirse como desalentador. No obstante, creemos que quienes tenemos la vocación de ser formadores, estamos ante un desafiante reto, que nos obliga a pensar lúcidamente nuestros proyectos formativos.

¿Aceptamos o nos rehusamos a ver que las instituciones escolares de los más variados niveles, se convierten en dispositivos de normalización? ¿Cómo proyectar nuestro quehacer si aceptamos que en Colombia hay serios problemas relacionados con la (des) estructuración de que son objeto miles de niños y de jóvenes desde su ambiente familiar? ¿Cómo proyectar la formación contable, si reconocemos que miles de nuestros estudiantes cada vez más tienen exiguas oportunidades de formar(-se) en condiciones económicas dignas? ¿Cómo desarrollamos nuestra misión universitaria, si asistimos sistemáticamente a un embate hacia la inclusión de la educación (cualquiera sea su nivel) en las lógicas de mercado? ¡En estas circunstancias, lo desolador ya se torna en devastador! Entonces, ya no se trata de que nuestras instituciones eduquen con calidad y propendiendo por la integralidad del ser humano, sino de competir entre nosotros mismos con un producto que tenga una jugosa 
rentabilidad y que satisfaga a los sujetos stultus hechos clientes.

No debe olvidarse que al incorporar la educación al circuito del mercado, no solo se la ve como un producto mediado por el sistema de precios $^{12}$, sino que se requiere además incluir la obsolescencia planificada. La destrucción creadora schumpeteriana significa que la innovación desplaza al producto previo del referente de utilidad simbólica ${ }^{13}$, para incrementar el ciclo de producción y consumo. Lo anterior implica, en educación, reducir el conocimiento formativo a la capacitación y dosificar la información para crear el ciclo de la educación "a lo largo de la vida". Joan DomenèchFrancesch (2009) nos alerta, cuando sentencia que la educación mediada por la mera información recrea en lo superfluo y crea una disposición a desaprender y cambiar cualquier referente previo, de manera rápida y sin remordimiento. Ahora, todo indica que un proyecto educativo, sin importar el campo de conocimiento, debe buscar la autogestión del individuo: un sujeto stultus se ve a sí mismo como una inversión que se debe gestionar. ¿Cómo será el porvenir de nuestra sociedad, si nuestros estudiantes se asumen como este tipo de sujetos y deciden ver su educación como una mera inversión que tendrá una alta tasa de retorno?

En síntesis, nos oponemos a la educación competitiva que se dirige a mantener la con-

12 Lo que se contrapone al ideario ilustrado moderno de constituir la educación en un derecho humano.

13 La obsolescencia en el capitalismo no se refiere necesariamente al agotamiento material del potencial de los productos-mercancías, sino al desplazamiento simbólico de la satisfacción del consumidor, tanto en su dimensión individual como social. dición de stultitia, que promueve que los individuos sean gerentes de sí mismos (Laval \& Dardot, 2013). Hace falta que nos indaguemos por qué gran parte de nuestros estudiantes desea el emprendimiento, aun cuando estudie campos como la filosofía o la química. ¿Cómo formar para el mundo de la vida, si el sujeto stultus no cuenta con los medios para resubjetivizarse bajo el saber que le inquieta su vida? La dinámica educativa dominante propone como núcleo la formación en competencias operativas (Barnett, 2001). Ser competente es la capacidad de "hacer lo que haya que hacer". La educación con fines de lucro invierte la lógica de la formación y bajo sus dispositivos, se pierde no solo la voluntad por la verdad, sino también la vocación, la ética, la profesionalidad (Nussbaum, 2010). Por supuesto, la educación con fines de lucro no es una respuesta solamente de la academia, sino un instrumento de quienes agencian un poder que funciona diseminadamente y utilizando al stultus que juega a todo para no perder todo. El entorno de cambio, la incertidumbre y el riesgo fluido nos victimizan y nos conducen a actuar en un juego de suma cero para el cultivo de épiméleia heautoû.

Tal vez muchos de los argumentos - tan evidentes para nosotros- pueden ser desestimados por algunos, pero desde allí nos hacemos las preguntas y nos damos al debate sobre: a) la orientación moral y ética de la educación contable; b) las pedagogías que relacionan los valores de mercado y los valores de la vida; c) la paulatina retirada de las ciencias humanas y sociales para comprender los fenómenos de valoración de los bienes humanos y culturales; d) la filosofía de la educación de los claustros universitarios. No 
es descabellado aseverar que la política de educación nacional (en sus diferentes niveles y manifestaciones) propone una desestructuración de la subjetividad de sí y exige, con la lógica del mercado, una educación deshumanizada, instrumentalista, que no facilita comprender los grandes problemas sociales del mundo; a la vez que infertiliza las potencialidades para operar la crítica, la alteridad y la transformación de la subjetividad humana.

Nos interesa aquí plantear por lo menos un par de ideas para comprender cómo esa educación contable termina promoviendo la subjetividad del stultus, chata, demasiado corta, muy pobre para la comprensión diversa y compleja del mundo. Nos interesa ver cómo la educación contable hace parte del engranaje que permite la emergencia de sujetos gobernables (Miller \& O'Leary, 1987/2009; Mennicken \& Miller, 2012).

\section{La educación contable: hacia la visibilización de sus impactos en la subjetividad}

La educación contable ha recibido importantes críticas: currículos agregados, exceso de formación técnica, orientación solo a la perspectiva de la contabilidad financiera, ausencia de formación humanística, ausencias pedagógicas en los docentes, pobreza en investigación, mayoría de programas en la modalidad de educación nocturna, estudiantes promedio que perciben su proceso de educación solo desde el ángulo de la movilidad social en sentido económico, ausencia de flexibilidad e interdisciplinariedad curricular, entre muchas otras consideraciones (Quijano-Valencia, Gra-
cia-López, Martínez-Pino, Ariza-Buenaventura \& Rojas-Rojas, 2002; Gracia, 2002; Ospina, 2009; ICFES, FIDESC, 2000; Loaiza, 2011; Rojas, 2008). Tales problemas del quehacer universitario contable han sido propios de los procesos de surgimiento y expansión de las facultades y programas de contaduría en el ámbito internacional y en el local (León-Paime, 2009). Estas características tienen impacto en la formación de los profesionales contables, pero - con todo y lo apremiante que es proponer soluciones - no son las más determinantes en el achatamiento de la capacidad simbólica, ética y estética de los estudiantes y egresados de la contaduría pública.

Planteamos que hay dos importantes esferas que resultan fundacionales para facilitar la resubjetivación de los estudiantes. En primer lugar, se ubican los conceptos, los valores y las reglas que son el objeto de educacióntransmisión, completamente alineados con la “operación” del modelo económico vigente, ultraliberal o financiarizado, pero vacío de análisis y referente contextuales que permitan repensar los diferentes relatos y tradiciones que pueblan nuestro mundo. En segunda instancia, la concepción del acto pedagógico con la cual se proponen acercamientos entre el docente y el estudiante sobre contenidos y problemas en particular.

Tal parece:

(...) que la única perspectiva, aparentemente integrada y con pretensiones de largo tiempo, es la que se identifica con el discurso empresarial, que en el plano de las ciencias sociales, se corresponde con una 
compartimentalización del conocimiento en áreas especializadas, con base en el pretexto de responder a requerimientos metodológicos que garanticen la construcción de un conocimiento sólido útil (...) (Zemelman, 2005, p. 23).

Lo anterior quiere decir conocimiento rentable. Por ello, resulta nodal que la educación contable finque todos sus esfuerzos en la capacitación en habilidades técnicas y en la operación de tecnologías "importadas”, bajo el modelo de copia-difusión. Tal importación o transferencia tecnológica se presenta hoy como "connatural" al proceso de globalización (Gil, 2001). En las estructuras curriculares ni siquiera se pregunta por la utilidad y solvencia de las técnicas-tecnologías importadas, ni se cuestiona por su eficacia-eficiencia para el contexto local. Desde nuestra posición, identificamos múltiples vacíos en los procesos curriculares. No hay un lugar para comprender al hombre y las relaciones sociales, políticas y axiológicas características de nuestra contemporaneidad. Incluso, desde un punto de vista simplemente funcional, tampoco se realizan preguntas sobre las necesidades de las organizaciones económicas concretas que deben enfrentar los futuros profesionales. Y bajo la égida de este campo de problemas eminentemente funcionales, se selecciona la porción de conocimientos que será recreada en las aulas para hacer "competentes" a los futuros contadores públicos.

Algunos se preguntan si acaso ese no es el papel de la universidad, formar en competencias profesionales: lo que salta a la vista entonces es una incomprensión del sentido de
"Universidad" y un acto irresponsable desde la concepción curricular por no intentar formar subjetividades comprometidas con la transformación social, sino meros operadores de sistemas. Los estudiantes, estos seres que vienen ya con tantas deficiencias formativas, cierran con broche de oro su proceso y resultan totalmente desprovistos para entenderse, para comprender a los otros, para actuar en democracia y ciudadanía y para ser seres sensibles, es decir, capaces de indignación (Hessel, 2011).

Esta formación centrada en técnicas, manuales, modelos y ecuaciones, no le permite al contador instalarse en una subjetividad crítica. En palabras de Hugo Zemelman, las técnicas resultan ser grandes trampas: "cuando se las maneja sin la claridad necesaria respecto de lo que significan, o sin el conocimiento de su lógica interna, terminamos por creer que la realidad posible de estudiarse es solo aquella que la técnica permite analizar" (2005, p. 68).

La educación contable atiborrada de modelos, técnicas, instrumentos, herramientas, formatos y diseños, queda inscrita en el mandato de la economía ultraliberal (recuerden que se necesitan sujetos dóciles y acríticos para el mercado de consumo), olvidando intencionadamente la comprensión de la naturaleza, de la sociedad, de la humanidad, de los grandes problemas epocales, de la historia, de la espiritualidad, del alma. Precisamente, al obviar estas dimensiones en la educación se generan problemas estructurales que luego repercuten en las crisis de la sociedad contemporánea ya que, como lo planteó Martha C. Nussbaum, tales “(...) facultades del pensamiento y la imaginación (...) nos hacen humanos y (...) 
fundan nuestras relaciones como relaciones humanas complejas, en lugar de meros vínculos de manipulación y utilización" (Nussbaum, 2010, p. 25).

La educación contable de raigambre instrumental mengua en el discente su reflexividad, pues "la libertad de pensamiento en el estudiante resulta peligrosa si lo que se pretende es obtener un grupo de trabajadores obedientes con capacitación técnica que lleven a la práctica los planes de las élites orientados a inversiones extranjeras y al desarrollo tecnológico" (Nussbaum, 2010, p. 46). Las visiones funcionales de la contabilidad, tanto sus fundamentos académicos como su instrumental práctico, limitan la capacidad para la construcción de un pensamiento contextual (Gómez, 2011).

La educación contable parte de instaurar en el sujeto, por medio de teorías, modelos y técnicas, conceptos para comprender y mediar sus relaciones con los otros y para concebirse a sí mismo. Los discentes que han transcurrido por la escolarización contable terminan suponiendo que el mercado funciona de manera perfecta, que todos los agentes son oportunistas que buscan siempre maximizar su beneficio individual y que, haciendo esto, todo confluye en el bienestar general. Que el mercado es una entidad abstracta (casi metafísica y ubicua) que asigna con una sabiduría providencial los recursos y que es infalible: ¡nadie engaña al mercado!, ¡ya lo ha descontado el mercado! En este contexto, la contabilidad solo provee información para que los mercados, particularmente financieros, funcionen bien. Nuestro principal interés debe girar alrededor de "satisfacer" las necesidades del inversor (Williams, 2006).
Por ello, por ejemplo, ahora el costo histórico no es conveniente, porque la contabilidad debe estar a valores de mercado, a Valor Razonable, suponiendo mercados perfectos. Esta es una muestra de la "episteme" constitutiva de los estudiantes de la contabilidad, acotando, achicando su subjetividad para entender el mundo.

$\mathrm{Al}$ mismo tiempo, los valores que se difunden, se presentan ante los sujetos como criterios técnicos, cuando en realidad constituyen entramados axiológicos, con coordenadas ideológicas específicas. Así, la eficiencia deja de ser una condición técnica, para convertirse en un valor para describir y calificar, ya no solo los procesos, sino a los individuos (Gómez, 2011). Pero la eficiencia abstracta nada tiene qué ver con la materia de la vida o de la producción. Comprar productos muy costo-eficientes, los más baratos, puede implicar riesgos, contaminación o aberraciones humanas en sus procesos productivos. Con ello, la eficiencia abstracta - antes que criterio técnico- se convierte en prescripción axiológica (Gómez, 2010). Por su parte, la eficacia, evaluada como el cumplimiento de los objetivos, se enfoca en la evaluación de los medios y deja fuera de todo juicio los objetivos mismos. Por ejemplo, con la hegemonía de las finanzas, toda actividad en la firma se abstrae al objetivo de maximizar el beneficio del accionista (el valor de la firma); no obstante, nunca se enjuician el fin mismo o los efectos de la eficacia perseguida (la reingeniería, las reestructuraciones por medio de operaciones de bolsa para inflar el precio de las acciones en bolsa, entre otras maniobras, son evidencia de los resultados de la hegemonía axiológica de criterios supuestamen- 
te técnicos). En síntesis, se utilizan criterios, aparentemente técnicos, para consolidar una hegemonía cultural y axiológica de las finanzas (Power, 2010).

Finalmente, la enseñanza basada en estándares, en códigos de conducta y en normas internacionales, promueve en el futuro profesional una discapacidad para juzgar y evaluar el contexto en su especificidad y para imaginar desenvolvimientos posibles de su propio ser. Todo lo que está por fuera del estándar está mal, está rezagado del "mundo", no es compatible con el entorno internacional. Se incluye así un mecanismo pedagógico aleccionador en el sujeto, que introduce valores y formas que no facilitan reconocer el contexto, sino imponer referencias para representar el contexto con un “deber ser" muy particularizado. En el ámbito ético, los códigos de conducta profesional promueven una retórica de servir al interés público (Baker, 2005/2009), cuando solo representan estratagemas de la gestión de los riesgos del corporativismo (Gómez, 2010). No se habla de acciones inconcebibles que desdicen de la independencia de criterio profesional, sino que se les califica de amenazas a la apariencia de independencia, que se evalúan a partir del peso financiero del contrato que genera el riesgo, en la cifra total de los "servicios prestados" (Williams, 2004; Gómez, 2010). Por consiguiente, se cambia la idea de la profesión con una función pública, por la de prestación de servicios, que debe garantizar la satisfacción del cliente (Zeff, 2003a, 2003b).

Por todo ello, podemos hacer diseños educativos flexibles, jugar con la retórica en la construcción de los proyectos educativos de programa, insertar humanidades agregadamente, capacitar a los profesores en pedagogía y didáctica universitarias, entre otras acciones. No obstante, los resultados no impactarán decisivamente esta tentativa de formación instrumental (Rojas \& Ospina, 2011), dado que se vuelve una situación incorregible, máxime si como profesores asumimos la postura del que siempre tiene la razón: “aquellos a quienes ni siquiera se les ocurre que es posible estar equivocado no pueden aprender otra cosa que habilidades prácticas" (Bateson, 2002, p. 36).

Este exceso de racionalidad tecnoinstrumental y la creciente configuración del sujeto posmoderno en la que se inscriben la mayoría de los estudiantes jóvenes, creemos, dan como resultado una subjetividad conforme con el presente de su sociedad. Sencillamente, debe reconocerse lúcidamente que las sociedades diferentes, que los mundos más incluyentes y de mayor equidad, requieren subjetividades críticas capaces de cuestionar y otear líneas de reconstrucción de lo establecido. Al margen, no sobra decir, que algunos estudiantes que logran hacer su propia imagen y configurar su lugar para el juicio ético y estético, lo hacen pese a la educación contable que reciben.

Del mismo modo, la pedagogía se ha puesto al servicio de esas necesidades hegemónicas. Es decir, se ha pedagogizado la racionalidad instrumental (Bauman, 2007). Cuando han aparecido o se han vivenciado modelos que permiten poner en cuestión las formas tradicionales, se han desvirtuado las bondades de tales alternativas. De un lado, la perspectiva tradicional, memorística, enciclopédica, vertical, autoritaria, pensada para un hombre disciplinado capaz de 
subordinarse y de responder eficientemente, un modelo que asume que la imagen más perfecta para lo humano es el funcionamiento maquinal, se muestra como más evidenciable, medible y fiable, por apalancarse en la tradición y la certeza de lo conocido. Esta concepción pedagógica todavía gobierna espacios formativos en la universidad y en los programas de contaduría pública (McPhail, 1999). Del otro lado, un modelo alternativo, horizontal, de aprendizaje compartido, dialógico, en el que cada quien tiene su voz y su derecho de expresión, en el que el juego reemplaza al concepto, laxo, de promoción automática, donde cada quien encuentra su ritmo, en el que el profesor ya no profesa con autoridad; este modelo promueve un individualismo irreflexivo y fortalece la relativización de los valores más significativos necesarios para armonizar el mundo de la vida. Si observamos este último escenario de lo pedagógico se vende a granel y, por supuesto, muchos currículos lo compran. Es importante reconocer que ambas propuestas están en los extremos de las sociedades que hemos vivido: la que promovió, en palabras de Hannah Arendt, la "aniquilación de la individualidad que caracterizó los regímenes totalitarios del siglo XX", y la más reciente referida al "individualismo del capitalismo tardío de la sociedad contemporánea, un individualismo que ha debilitado el sentido de comunidad y de tradición y acaba por reducir la vida humana en opciones concretas aquí y ahora" (Barone \& Mella, 2003, p. 199). En una perspectiva, el sujeto no tenía derecho a hablar o pensar y en la otra, bajo el supuesto de que todo lo que piense o hable es válido, se promueven el egoísmo y la incapacidad para comprender lo otro en senti- do colectivo y construir mínimos consensos en función de un ideal societario (Ospina, 2009). Este último modelo pedagógico fundado en las premisas del pensamiento posmodernista atenta contra la formación conceptual que requiere un mínimo de autoridad que proviene del compromiso con el saber y del compromiso con la comprensión compleja de una parte del mundo con los estudiantes (Domenèch, 2009). Ese compromiso es cada vez más ínfimo en el profesor. El profesor (algunos que pueblan nuestras universidades) ya no quiere saber más, ya no tiene un cariño especial por su espacio educativo, ya no quiere dar clase, prefiere que el estudiante lea guías y resuelva talleres en línea; ya no quiere responder preguntas, ya no quiere saber si hay nuevos temas o si los que sabe ya resultan obsoletos, ya no quiere ser problematizado, y las pocas clases que da son para vanagloriarse, para ofertar su narcisismo como fachada al temor de ser descubierto en su incapacidad comprensiva del mundo. En cambio, este profesor sí quiere ir a eventos, y como dice Martin Heidegger, no tiene biblioteca sino que se forma en seminarios. Sí quiere construir el nido en la universidad y hacer muchos puntos y ganarse sobresueldos y aparecer en los lugares donde aparecer sea culto imagológico.

Este modelo en el plano del proceso de enseñanza-aprendizaje, que hemos importado de a poco de Estados Unidos resulta en palabras de Hannah Arendt defectuoso:

Lo que hace tan aguda la crisis educativa americana es, pues, el carácter político del país, que lucha por igualar o borrar en la medida de lo posible las diferencias entre jóvenes y 
viejos, entre personas con talento y sin talento, entre niños y adultos, y en particular, entre alumnos y profesores. Es evidente que ese proceso puede cumplirse de verdad solo a costa de la autoridad del profesor y a expensas de los estudiantes más dotados (1996, p. 192).

Un modelo supuestamente participativo y supuestamente significativo en el cual lo importante es hablar, decir, tomar la palabra, parece hoy imponerse; pero como ha planteado el profesor Omar Aktouf ${ }^{14}$, hablar de qué si no se han aprehendido con certeza los conceptos que problematizan el campo disciplinar y el ejercicio profesional. De este modo, tanto en la perspectiva tradicional, como en la innovación pedagógica ofertada en el presente, no estamos haciendo mucho por la construcción de una subjetividad más compleja, porque no hemos centrado la atención en respondernos la siguiente pregunta: ¿qué hay que hacer en la educación contable para formar profesionales con criterio, ciudadanos con una subjetividad crítica, con una ética que ponga en el centro la dignificación humana?

Por consiguiente, la educación contable - por medio de contenidos conceptuales (la visión financiera del mundo social), valores implícitos y explícitos (individualismo, egoísmo, emprenderismo, exitismo) y mecanismos de disciplinamiento formal (códigos éticos y estándares profesionales, entre otros)—-se inscribe en la apuesta por un sujeto profesionalmente competente. Tal educación no permite

14 En sus clases en las maestrías de la Universidad del Valle y la Universidad EAFIT; también en sus conferencias. la construcción de un sujeto competente con su vida y con la de los demás, por una razón palmaria: porque no se le muestra qué es la naturaleza, qué es la sociedad, qué constituye la humanidad, el arte, la espiritualidad, la sensación, el alma, la necesidad del sentimiento de indignación; con este dibujo, nos preocupa que desde la educación contable se prohíje una forma de analfabetismo emocional, estético, político, en los profesionales de la contaduría pública.

Así mismo, con una pedagogía que no proyecta la idea de la gran responsabilidad que tiene el docente por reinterpretar partes del mundo con sus estudiantes, que no proyecta la necesidad de la formación conceptual, de la formación de la sensibilidad, que no se compromete por agotar los recursos para construir una idea cercana a la "verdad", lo que hacemos es reproducir las estéticas del presente.

No es pesimismo ni radicalismo ingenuo; para dondequiera que se mire, a este mundo le faltan seres que puedan meterse en la cabeza su funcionamiento y que tengan la voluntad para, por lo menos, transformar la subjetividad propia del stultus en que nos arropamos. La subjetividad que promueve la educación contable es tan chata que no deben espantarnos los adjetivos con los que se nos ve desde fuera: un mundo en el que la mayoría tiene su subjetividad enredada en el mercado de las oportunidades de morir "feliz" rodeado de objetos.

\section{Conclusión: de la necesidad de una educación contable para la resubjetivación}


Desde la condición de profesores y en atención a la problemática aquí expuesta, es muy fácil caer en una praxis acomodada y tranquila, cuando asumimos el mundo por dos vías: 1) porque nuestras necesidades, unas reales y otras predefinidas por el mercado, nos arrinconan de tal modo, que resulta muy conveniente hacer lo que sea para resolver nuestra condición material en la vida práctica, más bien, pragmática. El mundo y sus formas indignantes pasan por nuestro lado y escogemos voluntariamente una suerte de ignorancia para no perturbar nuestro espíritu. 2) Caemos en un eclecticismo-escepticismo bajo la idea de que una golondrina no hace verano y que, por tanto, cualquier intento por recrear la educación contable hacia horizontes de nuevas posibilidades de subjetivación es infructuoso, ingenuo y romántico. Que al ir contra la corriente, del mundo del ultraliberalismo, del mercado santificado, de los poderes corporativos, en suma, de las estéticas del presente hipermoderno, negamos a los estudiantes la oportunidad de ser exitosos y de escalar en la métrica del ascenso social. Que esto de ser profesor es un trabajo al que no cabe pedirle nada más, distinto a entregar un saber, evaluar la transmisión de dicho saber y llenar los formatos de registro calificado y acreditación.

Esta condición facilista (no desconocemos que haya profesores y maestros con un compromiso especial por turbar a los estudiantes y sacarlos de su condición autómata) arruina toda posibilidad por la construcción de un sujeto capaz de preocuparse por cuidarse y cuidar de los otros, por la imaginación de una educación que antes que mutilar una expresión humana más seductora y estética, le facilite a cada estu- diante hacer de sí un proyecto que valga la pena agenciar conscientemente.

Este tránsito de la stultitia a la sapientia (Foucault, 2001/2008) implica, obliga ante todo a que, como profesores, construyamos una imagen de nosotros mismos, como quien hace la mejor escultura de sí. Y esta tarea no se desarrolla asintiendo la lógica de los discursos que postulan algún escenario de crítica a la educación actual. Esta tarea implica formación, implica lugares para poder asir la nueva mirada, aquella que permita la reinvención del yo. Y para ello necesitaremos maestros, una guía filosófica que nos haga ver lo siempre oculto en nuestra condición de pasmosa velocidad en el mundo de los objetos y de lenta casi moribunda condición para saber de nosotros mismos.

Y si logramos mantener estas prácticas del cuidado de sí, podremos mostrarles algo del mundo a nuestros estudiantes y ayudarles a que ellos también se inquieten de sí mismos y de su entorno. "La inquietud de sí, en efecto, es algo que (...) siempre está obligado a pasar por el maestro, no hay inquietud de sí sin la presencia de un maestro. Pero lo que define la posición de este (el maestro) es que se preocupa por la inquietud que aquel a quien guía puede sentir con respecto a sí mismo" (Foucault, 2001/2008, p. 72).

Las tareas que quedan son las de redefinir la educación contable, siempre que los profesores y los gestores educativos intenten y busquen consolidar proyectos de formación que permitan la reconfiguración de las actitudes y prácticas de sí, en ellos mismos y sus estudiantes. 
Los seres humanos no nacen para siempre el día en que sus madres los alumbran, sino que la vida los obliga a parirse a sí mismos una y otra vez (García-Márquez, 2008).

Esperamos pues el debate natural de estas ideas para seguir construyendo posibles en el mundo de la educación contable y en la importante tarea de responsabilizarnos de los procesos de formación de los contadores públicos. Este artículo ha pretendido comprender esta relación entre subjetividad y educación contable. En una siguiente entrega, tenemos el compromiso de mostrar algunas rutas concretas de relación entre proyectos educativos en contaduría pública y resubjetivación.

\section{Referencias}

Arendt, Hannah (1996). La crisis de la educación, cap. V. En Entre el pasado y el futuro. Ocho ejercicios sobre la reflexión política, 185208. Barcelona: Península.

Baker, Richard (2005/2009). ¿Cuál es el significado de interés público? Examinando la ideología de la profesión de la contaduría pública americana. En Mauricio Gómez-Villegas \& Carlos Mario Ospina-Zapata (eds.) (2009). Avances interdisciplinarios para una comprensión crítica de la contabilidad. Textos paradigmáticos de las corrientes heterodoxas. Bogotá, Medellín: Escuela de Administración y Contaduría Pública, Universidad Nacional de Colombia y Departamento de Ciencias Contables, Universidad de Antioquia.
Barnett, Ronald (2001). Los límites de la competencia. El conocimiento, la educación superior y la sociedad. Barcelona: Gedisa.

Barone, Sabina \& Mella, Pablo (2003). Acción educativa y desarrollo humano en la universidad de hoy. Revista Iberoamericana de Educación, 31, 187-219. Disponible en: http:// www.redalyc.org/pdf/800/80003109.pdf

Bateson, Gregory (2002). Espíritu y naturaleza. Buenos Aires: Amorrortu Editores.

Bauman, Zygmunt (2007). Los retos de la educación en la modernidad líquida. Madrid: Gedisa.

Blackman, Lisa; Cromby, John; Hook, Derek; Papadopoulos, Dimitris \& Walkerdine, Valerie (2008). Creating Subjectivities. Subjectivity Journal, 22 (1), 1-22. Disponible en: http://www.palgrave-journals.com/sub/journal/v22/n1/full/sub20088a.html

Cruz-Kronfly, Fernando (1998). La tierra que atardece: ensayo sobre la modernidad y la contemporaneidad. Bogotá. Editorial Planeta.

Cruz-Kronfly, Fernando (2012). Educación \& formación: espacios de resistencia contra el proceso contemporáneo de reducción de cabezas. Documento presentado a V Seminario Internacional de Nuevo Pensamiento Administrativo. Cali, Universidad del Valle. Texto previo disponible en: http://www.eafit.edu. co/revistas/forum-doctoral/Documents/ed3/ EDUCACION-FORMACION-(2).pdf

Domenèch-Francesch, Joan (2009). Elogio de la educación lenta. Barcelona. Editorial Graó.

Dufour, Dany Robert (2007a). Crítica de la postmodernidad. Gobernanza y gobierno. Santiago de Cali: Universidad del Valle. 
Dufour, Dany Robert (2007b). El arte de reducir cabezas. Sobre la servidumbre del hombre liberado en la era del capitalismo total. Buenos Aires: Paidós.

Fernández, Ana María (2013). Jóvenes de vidas grises. Psicoanálisis y biopoderes. Buenos Aires: Nueva Visión.

Foucault, Michel (1986). Vigilar y castigar, nacimiento de la prisión. Madrid: Siglo XXI Editores.

Foucault, Michel (1988). El sujeto y el poder. Revista Mexicana de Sociología, 50 (3), 3-20. Disponible en: http://terceridad.net/ wordpress/wp-content/uploads/2011/10/ Foucault-M.-El-sujeto-y-el-poder.pdf

Foucault, Michel (1994). ¿Qué es la Ilustración? Revista Actual, 28, 19-44.

Foucault, Michel (2001/2008). La hermenéutica del sujeto. Buenos Aires: Fondo de Cultura Económica, FCE.

Foucault, Michel (2009). El yo minimalista y otras conversaciones. Buenos Aires: La Marca Editora.

García-Canclini, Néstor (1995). Culturas híbridas. Estrategias para entrar y salir de la modernidad. México: Grijalbo.

García-Márquez, Gabriel (2008). El amor en los tiempos del cólera. Bogotá: Norma.

Giddens, Anthony (1996). Modernidad y autoidentidad. En Josetxo Beriain (comp.). Las consecuencias perversas de la modernidad: modernidad, contingencia y riesgo. Barcelona: Anthropos.

Gil, Jorge Manuel (2001). Normas internacionales de contabilidad y transferencia de tecnología. Revista Legis del Contador, 6, 87-102.
Gómez-Villegas, Mauricio (2010). Interés público y ejercicio de la contaduría pública. Miradas al contexto internacional y aprendizaje para la profesión en Colombia. Revista UNIMAR, 54. Disponible en: HYPERLINK "http://www.umariana.edu.co/ RevistaUnimar/publicaciones/RevistaUnimar54.html\%23/78/" http://www.umariana.edu.co/RevistaUnimar/publicaciones/ RevistaUnimar54.html\#/78/

Gómez-Villegas, Mauricio (2011). Pensando los fundamentos de la contabilidad como disciplina académica. Lúmina, 12, 120-150. Disponible en:http://www.umanizales.edu.co/ publicaciones/campos/economicas/lumina/ recusos/12/7_pensando.pdf

Gracia, Édgar (2002). Estado actual de la educación contable en Colombia. En Olver Quijano-Valencia, Édgar Gracia-López, Guillermo León Martínez-Pino, Efrén Danilo Ariza-Buenaventura \& William Rojas-Rojas. Del hacer al saber. Realidades y perspectivas de la educación contable en Colombia. Popayán: Universidad del Cauca.

Gracia, Édgar (2010). La investigación contable en el acto educativo. Contaduría Universidad de Antioquia, 57, 255-269. Disponible en: http://aprendeenlinea.udea.edu.co/ revistas/index.php/cont/article/viewFile/15588/13530

Hardt, Michael \& Negri, Antonio (2012). Declaración. Madrid: Akal.

Hessel, Stéphane (2011). ¡Indignaos! Un alegato contra la indiferencia y la insurrección pacífica. Madrid. Editorial Destino.

Instituto Colombiano para la Evaluación de la Educación, ICFES \& Fundación para la In- 
vestigación y Desarrollo de la Ciencia Contable, FIDESC (2000). La contaduría pública del nuevo milenio. Bogotá: ECOE Ediciones, FIDESC.

Laval, Christian \& Dardot, Pierre (2013). La nueva razón del mundo. Ensayo sobre la sociedad neoliberal. Barcelona: Gedisa Editorial.

Leff, Enrique (2004). Racionalidad ambiental. La reapropiación social de la naturaleza. México: Siglo XXI Editores.

León-Paime, Edison Fredy (2009). La educación contable en el contexto anglosajón: una mirada a los años de construcción de comunidad. Cuadernos de Contabilidad, 10 (27), 219-245. Disponible en: http://revistas.javeriana.edu.co/index.php/cuacont/article/view/3208

Loaiza-Robles, Fabiola (2009). Producción académica sobre educación contable en Colombia: incidencia de la pedagogía crítica. Lúmina, 12, 172-194. Disponible en: http:// www.umanizales.edu.co/publicaciones/ campos/economicas/lumina/recursos/12/9_ produccion.pdf

McPhail, Ken (1999). The Threat of Ethical Accountants: An Application of Foucault's Concept of Ethics to Accounting Education and some Thoughts on Ethically Educating for the Other. Critical Perspectives on Accounting, 10 (6), 833-866.

Mennicken, Andrea \& Miller, Peter (2012). Accounting, Territorialization and Power. Foucault Studies, 13, 4-24. Disponible en: http:// www.lse.ac.uk/accounting/pdf/Mennickenand-Miller-2012.pdf
Miller, Peter \& O'Leary, Ted (1987/2009). La contabilidad y la construcción de la persona gobernable. En Mauricio GómezVillegas \& Carlos Mario Ospina-Zapata (eds.) (2009). Avances interdisciplinarios para una comprensión crítica de la contabilidad. Textos paradigmáticos de las corrientes heterodoxas. Bogotá, Medellín: Escuela de Administración y Contaduría Pública, Universidad Nacional de Colombia y Departamento de Ciencias Contables, Universidad de Antioquia.

Nussbaum, Martha C. (2010). Sin fines de lucro. Por qué la democracia necesita de las humanidades. Buenos Aires: Ketz

Ospina-Zapata, Carlos Mario (2009). Educación contable en Colombia: sentires de algunos actores y la educación contable como acción educativa. Contaduría Universidad de Antioquia, 55, 11-40. Disponible en: http:// aprendeenlinea.udea.edu.co/revistas/index. php/cont/article/viewFile/16336/14169

Power, Michael (2010). Fair Value Accounting, Financial Economics and the Transformation of Reliability. Accounting and Business Research, 40 (3), 197-210.

Quijano-Valencia, Olver; Gracia-López, Édgar; Martínez-Pino, Guillermo León; Ariza-Buenaventura, Efrén Danilo \& Rojas-Rojas, William (2002). Del hacer al saber. Realidades y perspectivas de la educación contable en Colombia. Popayán: Universidad del Cauca.

Rojas-Rojas, William (2008). Congoja por una educación contable fútil. Contaduría Universidad de Antioquia, 52, 259-274. Disponible en: http://aprendeenlinea.udea.edu. 
co/revistas/index.php/cont/article/viewFile/2171/1765

Rojas-Rojas, William \& Ospina-Zapata, Carlos Mario (2011). Consideraciones sobre el sentido de un proyecto educativo en Contaduría Pública. Cuadernos de Administración, 45 (27), 45-60. Disponible en: http://www.redalyc.org/articulo.oa?id=225019868004

Romero, José Luis (1987). Estudios de la mentalidad burguesa. Madrid: Alianza Editorial.

Steiner, George (2012). Gramáticas de la creación. Buenos Aires: Debolsillo.

Williams, Paul F. (2004). You Reap What you Sow: the Ethical Discourse of Professional Accounting. Critical Perspectives on Accounting, 15, 995-1001. Disponible en: file:///D:/
Mis\%20documentos/Downloads/sdarticle_019_177881.pdf

Zeff, Stephen (2003a). How the U.S. Accounting Profession Got Where it is Today: Part I. Accounting Horizons, 17 (3), 189-205.

Zeff, Stephen (2003b). How the U.S. Accounting Profession got where it is today: Part II. Accounting Horizons, 17 (4), 267-286.

Zemelman, Hugo (2005). Voluntad de conocer. El sujeto y su pensamiento en el paradigma crítico. Madrid: Anthropos.

- Fecha de recepción: 25 de septiembre de 2013

- Fecha de aceptación: 28 de enero de 2014

Para citar este artículo

Ospina-Zapata, Carlos Mario; Gómez-Villegas, Mauricio \& Rojas-Rojas, William (2014). La constitución de la subjetividad en la educación contable: del proceso implícito a la visibilización de sus impactos. Cuadernos de Contabilidad, 15 (37), 187211. 
